\title{
New findings of Middle Stone Age lithic artifacts from the Matmata loess region in southern Tunisia
}

\author{
Dominik Faust ${ }^{1}$, Sebastian Kreutzer ${ }^{2,3}$, Yesmine Trigui ${ }^{1}$, Maximilian Pachtmann ${ }^{1}$, Georg Mettig ${ }^{1}$, Moncef Bouaziz ${ }^{1}$, \\ Jose Manuel Recio Espejo ${ }^{4}$, Fernando Diaz del Olmo ${ }^{5}$, Christoph Schmidt ${ }^{6}$, Tobias Lauer ${ }^{7}$, Zeljko Rezek ${ }^{7,8}$, \\ Alexander Fülling ${ }^{9}$, and Sascha Meszner ${ }^{1,10}$ \\ ${ }^{1}$ Chair of Physical Geography, TU Dresden, Dresden, Germany \\ ${ }^{2}$ Geography \& Earth Sciences, Aberystwyth University, Aberystwyth, UK \\ ${ }^{3}$ IRAMAT-CRP2A, UMR 5060, CNRS - Université Bordeaux Montaigne, Pessac, France \\ ${ }^{4}$ Fac. de Ecología, Universidad de Córdoba, Córdoba, Spain \\ ${ }^{5}$ Dep. de Geografía Física, Universidad de Sevilla, Seville, Spain \\ ${ }^{6}$ Chair of Geomorphology, Universität Bayreuth, Bayreuth, Germany \\ ${ }^{7}$ Department of Human Evolution, Max Planck Institute for Evolutionary Anthropology, Leipzig, Germany \\ ${ }^{8}$ Museum of Archaeology and Anthropology, University of Pennsylvania, Philadelphia, USA \\ ${ }^{9}$ Geologisches Institut, Universität Freiburg, Germany \\ ${ }^{10}$ JENA-GEOS-Ingenieurbüro GmbH, Jena, Germany
}

Correspondence: Dominik Faust (dominik.faust@tu-dresden.de)

Relevant dates: $\quad$ Received: 26 November 2019 - Revised: 10 March 2020 - Accepted: 1 April 2020 Published: 27 May 2020

How to cite: $\quad$ Faust, D., Kreutzer, S., Trigui, Y., Pachtmann, M., Mettig, G., Bouaziz, M., Recio Espejo, J. M., Diaz del Olmo, F., Schmidt, C., Lauer, T., Rezek, Z., Fülling, A., and Meszner, S.: New findings of Middle Stone Age lithic artifacts from the Matmata loess region in southern Tunisia, E\&G Quaternary Sci. J., 69, 55-58, https://doi.org/10.5194/egqsj-69-55-2020, 2020.

\section{Geographical setting}

The Matmata Plateau in southern Tunisia is a midCretaceous limestone plateau also called the Dahar highlands which lies at an elevation between 400 and $700 \mathrm{~m}$ a.s.l.. The plateau is located at the extreme northern margin of the Sahara, between the Gulf of Gabès to the east and the Grand Erg Oriental to the west (Fig. 1). On the plateau, several large basins filled up with sandy loess are situated around the villages of Matmata and Techine (Coudé-Gaussen and Rognon, 1986). Two of these basins, named the Matmata basin (MB) and Techine basin (TB), host the loess-paleosol sequences (LPS) studied here. Because the loess sediments are highly dissected and feature extremely steep slopes, the profiles are easily accessible.

\section{Methods}

Most of the work was carried out during several field trips. After a long-lasting prospection phase, during which we opened as many profiles as possible, we decided to select the nine most representative LPS for detailed geochemical and granulometric analyses and dating (Fig. 2). Archeological investigations were actually never planned, but we always kept an eye out for potentially interesting findings. The chronological framework is ongoing work by the means of optically stimulated luminescence (OSL) and infraredradiofluorescence (IR-RF) dating (OSL - Huntley et al., 1985; IR-RF - Trautmann et al., 1998, 1999; Frouin et al., 2017) as a joint effort of four different laboratories located at the University of Bayreuth (Germany), the Max Planck In- 


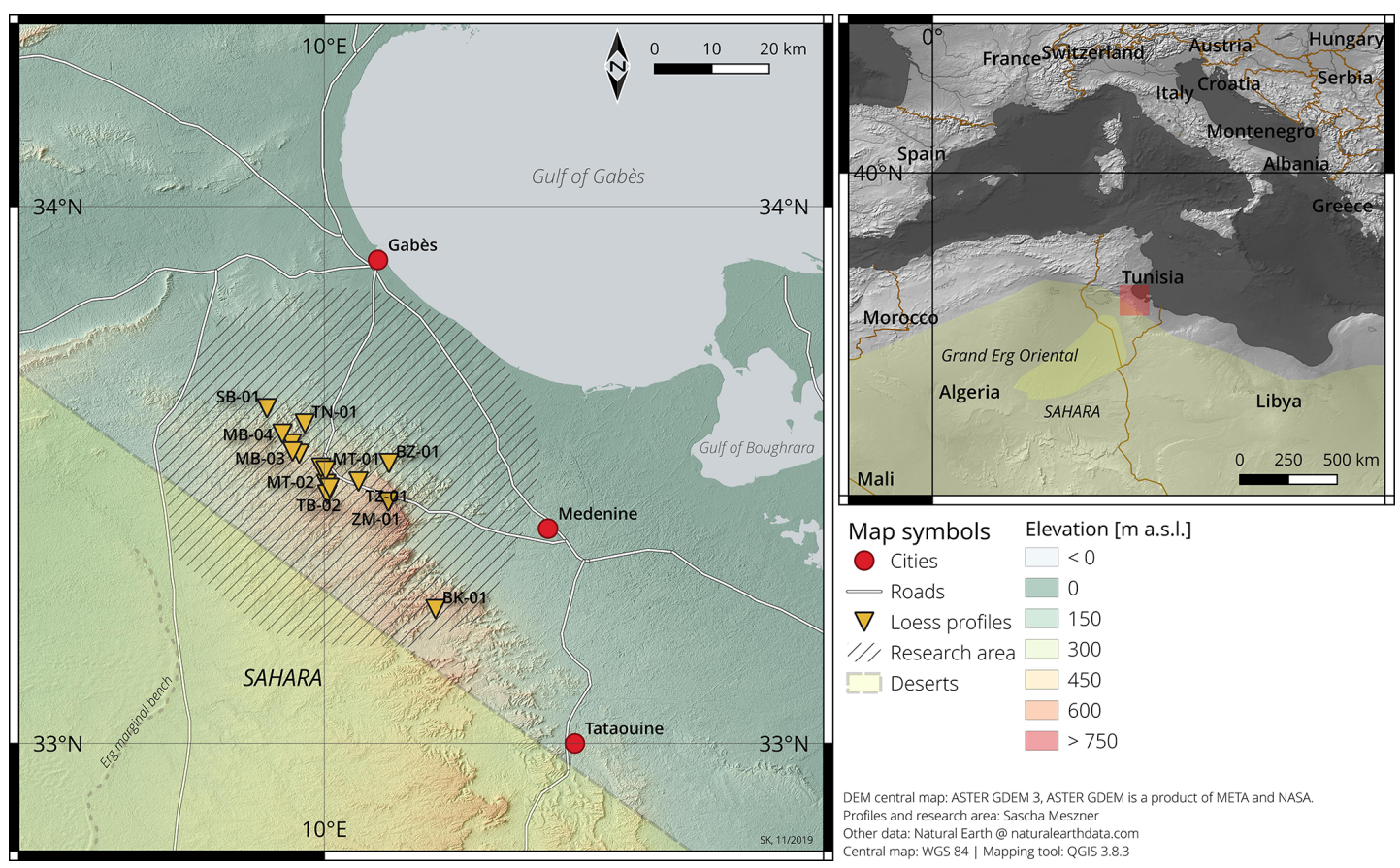

Figure 1. Location of the study area and the investigated profiles (source: (C) Google maps).
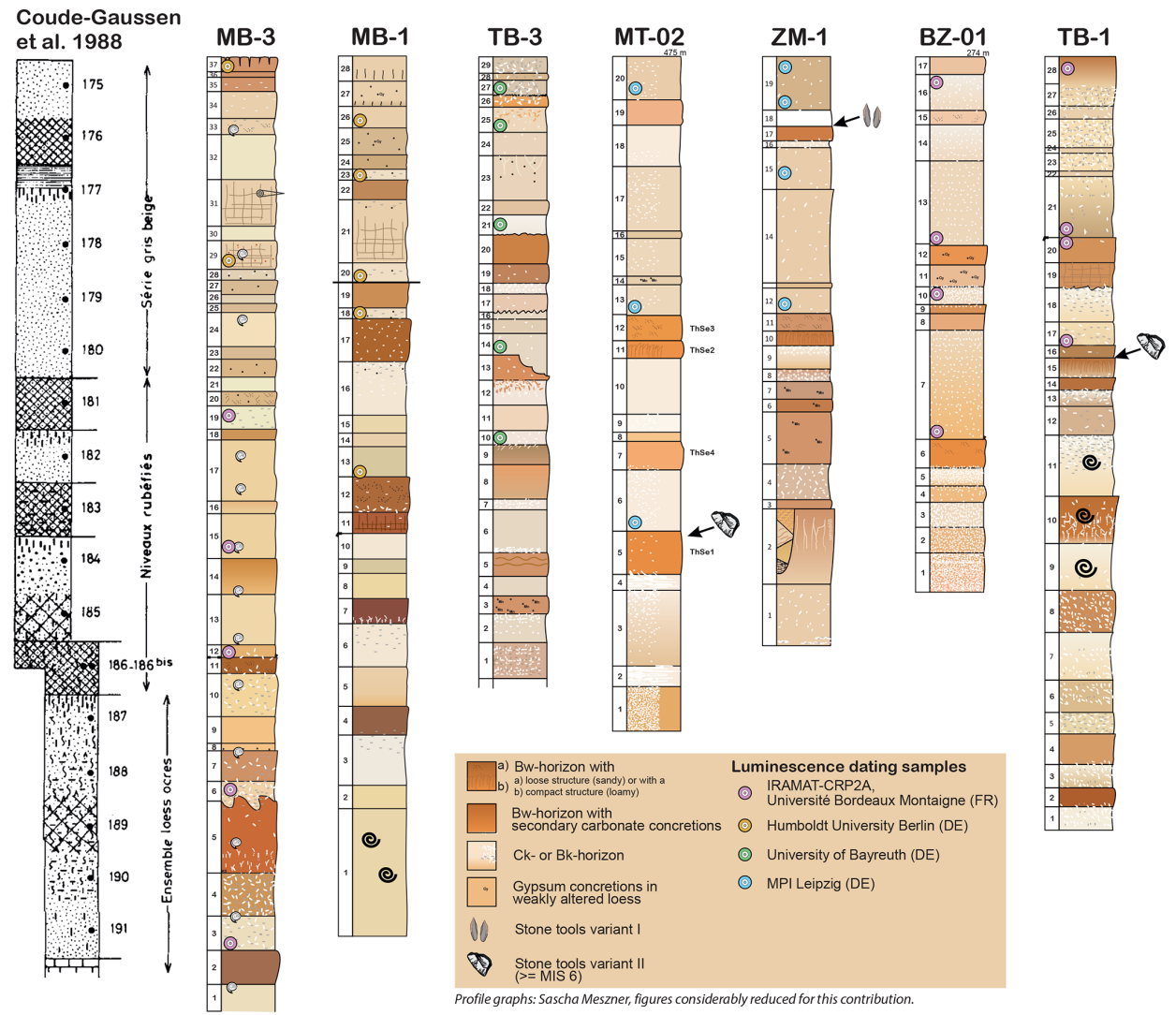

Figure 2. Profile compilation of the Matmata loess region (southern Tunisia) supported by a model of Caude-Gaussen and Rognon (1988). In TB-1 and MT-02 we found artifacts of the African Middle Stone Age in an open-site setting. The luminescence age estimates should be understood as preliminary; changes are possible. 


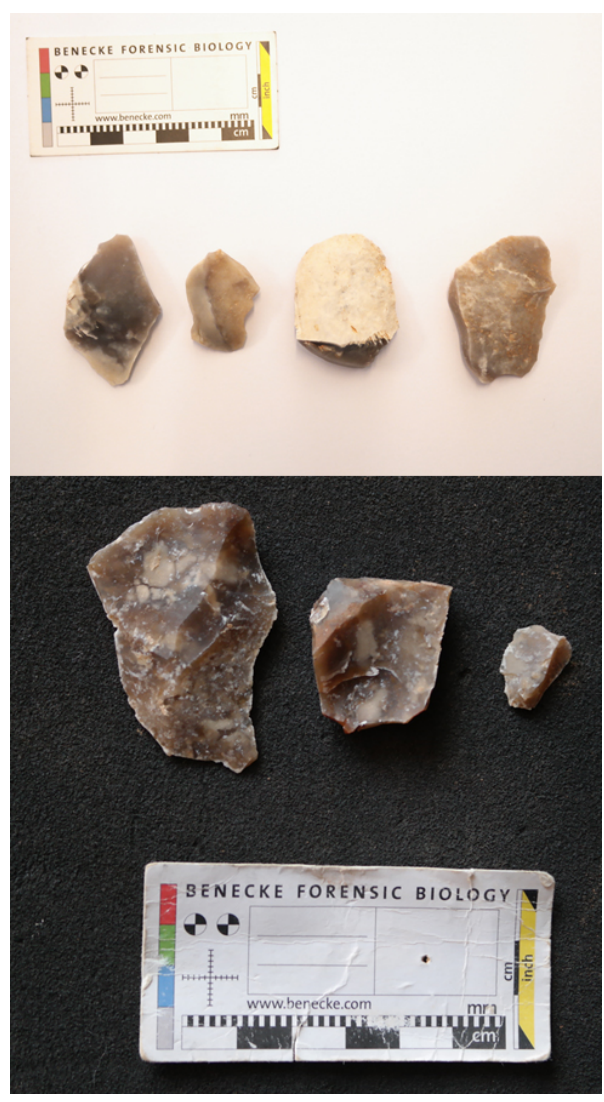

Figure 3. Selection of artifacts from the TB-1 profile.

stitute for Evolutionary Anthropology in Leipzig (Germany), the Université Bordeaux Montaigne (France) and the University of Freiburg (Germany).

\section{First results}

The original aim of the project was the reconstruction of paleoenvironmental conditions during loess sedimentation and soil formation phases. In this short communication, however, we focus on lithic artifacts found by chance during fieldwork. The chronology is still preliminary and allows only a rough temporal framework. However, our still-ongoing luminescence dating indicates that the lithic artifacts can be attributed to the marine isotope stage (MIS) 6 or older. Stone artifacts made of fine-grained flint (Fig. 3) were found on top of a paleosol in two locations (Fig. 4; for orientation see Fig. 2; TB- 1 is $33.48162^{\circ} \mathrm{N}, 10.00782^{\circ} \mathrm{E}$, and MT-02 is $33.51820^{\circ} \mathrm{N}, 9.99644^{\circ} \mathrm{E}$ ). Combining both locations, the collection comprises 23 unretouched complete flakes larger than $2 \mathrm{~cm}$, which are cortical, partially cortical and noncortical. We also found stone artifacts in a couple of other sections (20 complete flakes and flake fragments), albeit without exact stratigraphic context (the artifacts were washed out and transported downslope). The location of the artifacts found on paleosols is shown in Fig. 2. The age attribution has to

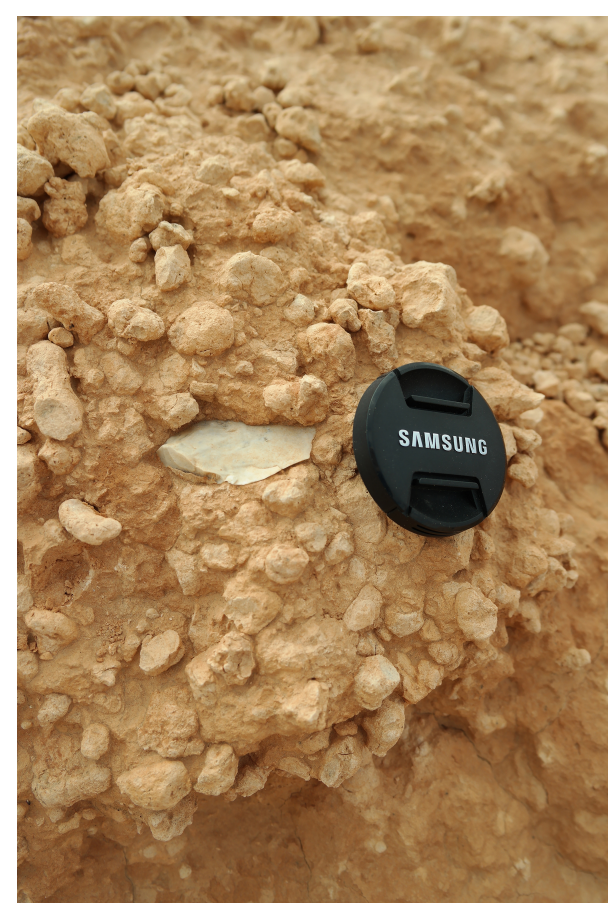

Figure 4. Stone artifact in its position found in TB-1 on a paleosol.

be corroborated by further luminescence dating efforts, but even the possible minimum chronological placement in MIS 6 renders these findings the oldest stone tools ever found in Tunisia (see Aouadi-Abdeljaouad and Belhouchet, 2017). Currently, the oldest reported Middle Stone Age deposits in Tunisia originate from Oued El Akarit, about $30 \mathrm{~km}$ north of Gabès, dated to around $80 \mathrm{ka}$ (thermoluminescence on flint artifacts; Reyss et al., 2007). Ages older than this are also presented in Reyss et al. (2007) but highly questioned due to severe dosimetric problems. In a subsequent publication, we plan to provide more detailed contextual information on the as yet provisional chronology presented here. Nevertheless, our preliminary findings suggest that the Matmata loess region as an extraordinary sedimentary archive could potentially play a major role in reconstructing past environmental conditions of human mobility and survival in central northern Africa in this period.

\section{Outlook}

Our multinational project enriches the reconstruction of paleoenvironmental conditions in central northern Africa with a further aspect. The number of artifacts found suggests the presence of humans in this region during the more humid soil formation phases. The next step will be to increase the sample size of archeological material during future fieldwork seasons. 
Data availability. No data sets were used in this article.

Author contributions. DF wrote the text, corrected the text several times, is the PI of the team and took part in two field trips. SK is responsible for dating activities in the Bordeaux lab and elaborated some figures and was involved in the revision process. YT coordinates our work in Tunisia and took part in some field trips. MP took part in all field trips and did his Master's thesis in this area. We changed some figures that we took out of his thesis. GM took part in all field trips and did his Master's thesis in this area. We changed some figures that we took out of his thesis. MB coordinated the project and took part in almost all the field trips. JMRE and FDdO realized all the clay mineral analyses. CS was responsible for dating in Bayreuth and took part in field trips. TL was responsible for dating and took part in a field trip. ZR was responsible for archeological determinations and took part in a field trip. AF was responsible for dating activities in Freiburg. SM was the project leader in Tunisia; he took part in every field trip and was the second leader of the project. Finally he did all the preparation work for this express report.

Competing interests. The authors declare that they have no conflict of interest.

Acknowledgements. Our work was supported by the GermanArab Transformation Partnership program of the DAAD in the framework of the project "Aeolian dynamics in Tunisia - past and present".

The work of Sebastian Kreutzer has been financed by the LaScArBx LabEx, a program supported by the ANR - no. ANR-10LABX-52, and since 2020 by the European Union's Horizon 2020 research and innovation program under the Marie SkłodowskaCurie grant agreement no. 844457 . We thank the handling associate editor, the reviewer Eduard Pop and one anonymous reviewer for fruitful comments.

Financial support. This research has been supported by the DAAD.

The article processing charge was funded by the Quaternary scientific community, as represented by the host institution of EGQSJ, the German Quaternary Association (DEUQUA).

Review statement. This paper was edited by Christopher Lüthgens and reviewed by Eduard Pop and one anonymous referee.

\section{References}

Aouadi-Abdeljaouad, N. and Belhouchet, N.: Middle Stone Age in Tunisia: Present status of knowledge and recent advances, in: Modern Origins, edited by: Hublin, J. J. and McPherron, S., Vertebrate Paleobiology and Paleoanthropology, Springer, Dordrecht, 143-155, 2017.

Coudé-Gaussen, G. and Rognon, P.: Paléosols et loess du Pleistocène supérieur de Tunisie et d'Israël, Quaternaire, 1986.

Coudé-Gaussen, G. and Rognon, P.: The Upper Pleistocene Loess of Southern Tunisia. A Statement, Earth Surf. Proc. Land., 13, 137-151, 1988.

Frouin, M., Huot, S., Kreutzer, S., Lahaye, C., Lamothe, M., Philippe, A., and Mercier, N: An improved radiofluorescence single-aliquot regenerative dose protocol for K-feldspars, Quat. Geochronol., 38, 13-24, https://doi.org/10.1016/j.quageo.2016.11.004, 2017.

Huntley, D. J., Godfrey-Smith, D. I., and Thewalt, M. L. W.: Optical dating of sediments, Nature, 313, 105-107, https://doi.org/10.1038/313105a0, 1985.

Reyss, J.-L., Valladas, H., Mercier, N., Froget, L., and Joron, J.-L.: Application des méthodes de la thermoluminescence et des déséquilibres dans la famille de l'uranium au gisement archéologique d'El Akarit, in: El Akarit Un Site Archéologique Du Paléolithique Moyen Dans Le Sud De La Tunisie. Editions Recherche sur les Civilisations, Paris, 357-363, 2007.

Trautmann, T., Krbetschek, M. R., Dietrich, A., and Stolz, W.: Investigations of feldspar radioluminescence: potential for a new dating technique, Radiat. Meas., 29, 421-425, https://doi.org/10.1016/S1350-4487(98)00012-2, 1998.

Trautmann, T., Krbetschek, M. R., Dietrich, A., and Stolz, W.: Feldspar radioluminescence: a new dating method and its physical background, J. Lumin., 85, 45-58, https://doi.org/10.1016/S0022-2313(99)00152-0, 1999. 